\title{
Factors Affecting Energy Efficiency Investments-A Case Study of Bhutan
}

\author{
Roshan Chhetri ${ }^{1}$, Young-Ho LEE ${ }^{2}$, Duane Robinson ${ }^{3}$ and Sumitra Pokhrel ${ }^{4}$ \\ 1. Department of Electrical Engineering, College of Science and Technology, Royal University of Bhutan, Phuentsholing, P.O. Box \\ 450, Bhutan
}

2. Division of Mechanical Engineering, Korea Maritime and Ocean University, Busan 606 791, South Korea

3. Sustainable Building Research Centre University of Wollongong, NSW 2522, Australia

4. Phuentsholing Higher Secondary School, Phuentsholing, Bhutan

\begin{abstract}
Energy efficiency is providing the same services consuming less energy. Less energy means less energy bill and less greenhouse emissions. Bhutan presents a unique scenario in promoting the use of energy efficiency equipment and investments. Bhutan enjoys availability of adequate low cost hydropower energy resource that is green and clean and enjoys cheap electrical energy. To aggravate the situation, the domestic tariffs are subsidized and even free up to 100 units in rural parts of the country. Export tariffs are determined independently according to entirely different principles. However for cooking, Bhutan imports LPG (Liquefied Petroleum Gas) from India. With increasing threats of climate change, it is reported water flow in rivers is decreasing. For energy security and related socio environmental issues, prospects of energy supply constraints and increasing demand of quality power in the country, there is a need to take appropriate policy measures which would lead to the development of indigenous, local and dispersed clean energy sources in the future. When a customer is asked to retrofit the house with energy efficiency, the owner questions oneself if the available investment resources are being directed to an effective return. Various criteria are available but all can not to be considered to come to a final decision. This paper presents an overview of many factors which affect energy efficiency investment in building in Bhutan.
\end{abstract}

Key words: Energy efficiency, policies, retrofits, incentives.

\section{Introduction}

Bhutan is one of the Asia's smallest nations, with the population of just above 700,000, landlocked between the extensive borders of the two great populous nations of China and India. The climate varies from cool summers and severe winters in north to subtropical summers and mild winters in south. The altitude ranges from the southern foothills, $100 \mathrm{~m}$ above the mean sea level, extending into the northern mountain peaks that are over 7,500 $\mathrm{m}$ in height. These high rise mountains form the watershed to the river systems of Bhutan which contributes to the extraction of hydro energy.

Corresponding author: Roshan Chhetri, MScE (EE), asst. professor, research fields: unit commitment, energy efficiency, power system.
Bhutan's primary resource for electric power generation is hydropower. Of the total $30 \mathrm{GW}$ theoretical hydropower potential, $24 \mathrm{GW}$ is technically potential and only about $1.6 \mathrm{GW}$ stands harnessed till date. However, rapid developments of numerous new hydropower projects are being currently carried out with a target $10 \mathrm{GW}$ generation by the year 2020 .

The BEA (Bhutan Electricity Authority) was established in 2001 (full autonomous in Jan. 2010) to restructure and regulate the electricity supply industry and to allow private sector participation in the electricity supply industry. BEA processes applications and issue, modifies and revokes licences for generation, transmission, system operation, export, import, distribution and sale of electricity. Bhutan 
Sustainable Hydropower Development Policy 2008 was initiated to mobilize funds and attract investments for accelerating hydropower development.

After the construction of RGoB hydropower is over and commissioned, it will be fully managed by Druk Green Power Corporation Limited (DGPC), while the Bhutan Power Corporation Limited (BPC) manages transmission and distribution system. The power system operator called National Load Dispatch Center (NLDC) is established with effect from July 2014 to work on Bhutan power network, which works in interconnection with the Indian grid.

Rivers flows in Bhutan are low in the winter and high flow during summer caused by monsoon precipitation and melting of glacier ice and snow. The glacier and snows are formed during winter due to low temperatures on mountain peaks. Due to the vulnerability of the water supply amid climate change, the Bhutanese government began exploring alternative energies like solar, wind and biogas. With the mission electricity for all, grid connection for small communities remains unattractive to commercial providers due to their relatively low power consumption [1]. These communities are provided with solar lighting and energy efficiency is vital for them. Renewable energy policy is also being drafted. The question here is whether we should only depend on renewable energy policies and alternative energies. Is it not time for us to reduce energy consumption by investing on energy efficiency without compromising comfort and productivity? Energy efficiency will also improve energy security.

Some of the factors that affect investments on energy efficiency in Bhutan are availability of energy and tariff, policies, customer, market, building architecture and technology.

\section{Energy Demand}

The domestic demand of power is showing an increasing trend, while the supply will remain stagnant till the commissioning of some ongoing projects. According to the figures with the ministry of economic affairs, the demand will increase from 256.9 MW in 2010 to 376 MW in 2016 and 407 MW in 2018 [2].

\section{Energy Resource and Use}

Traditionally, firewood has been the major source of energy for a large number of rural and urban households in Bhutan. However according to Asian Development Bank (Report 2012) it says that electricity is the main energy source for lighting in $88 \%$ of households (98\% in the urban areas, $83 \%$ in the rural areas). In the rural areas, $12 \%$ of households use

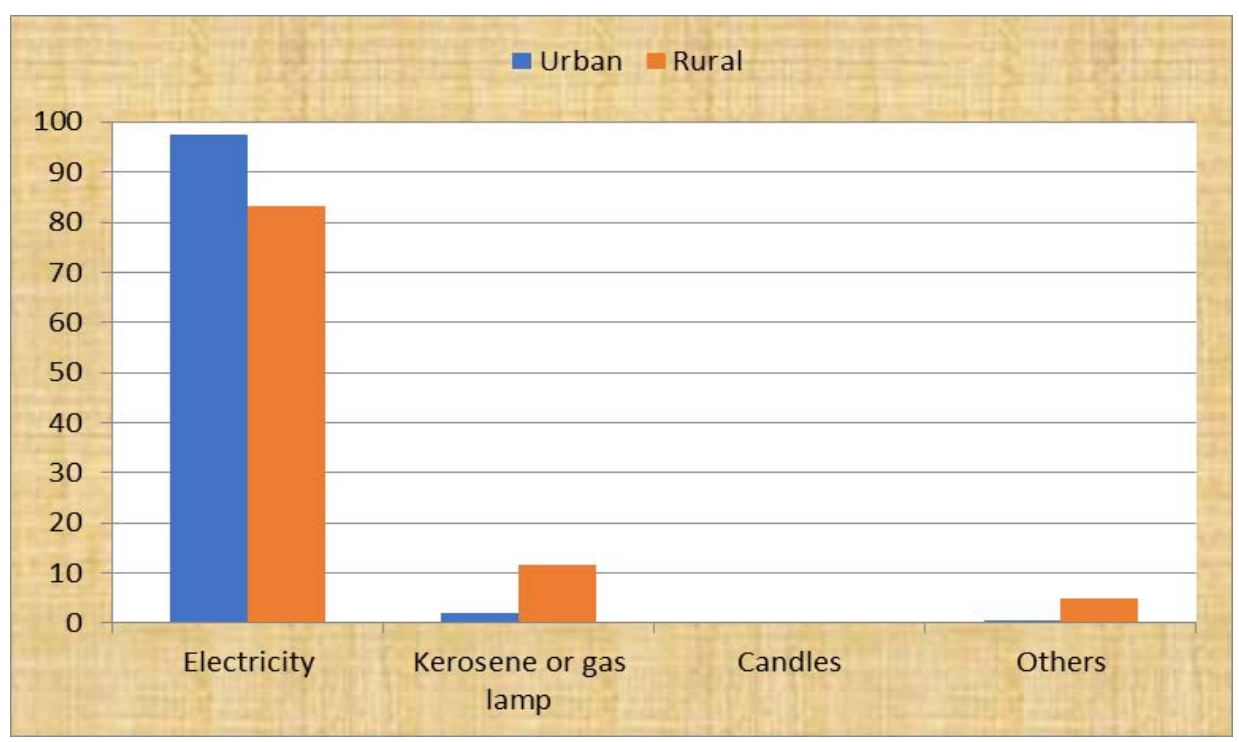

Fig. 1 Lighting sources of energy. 


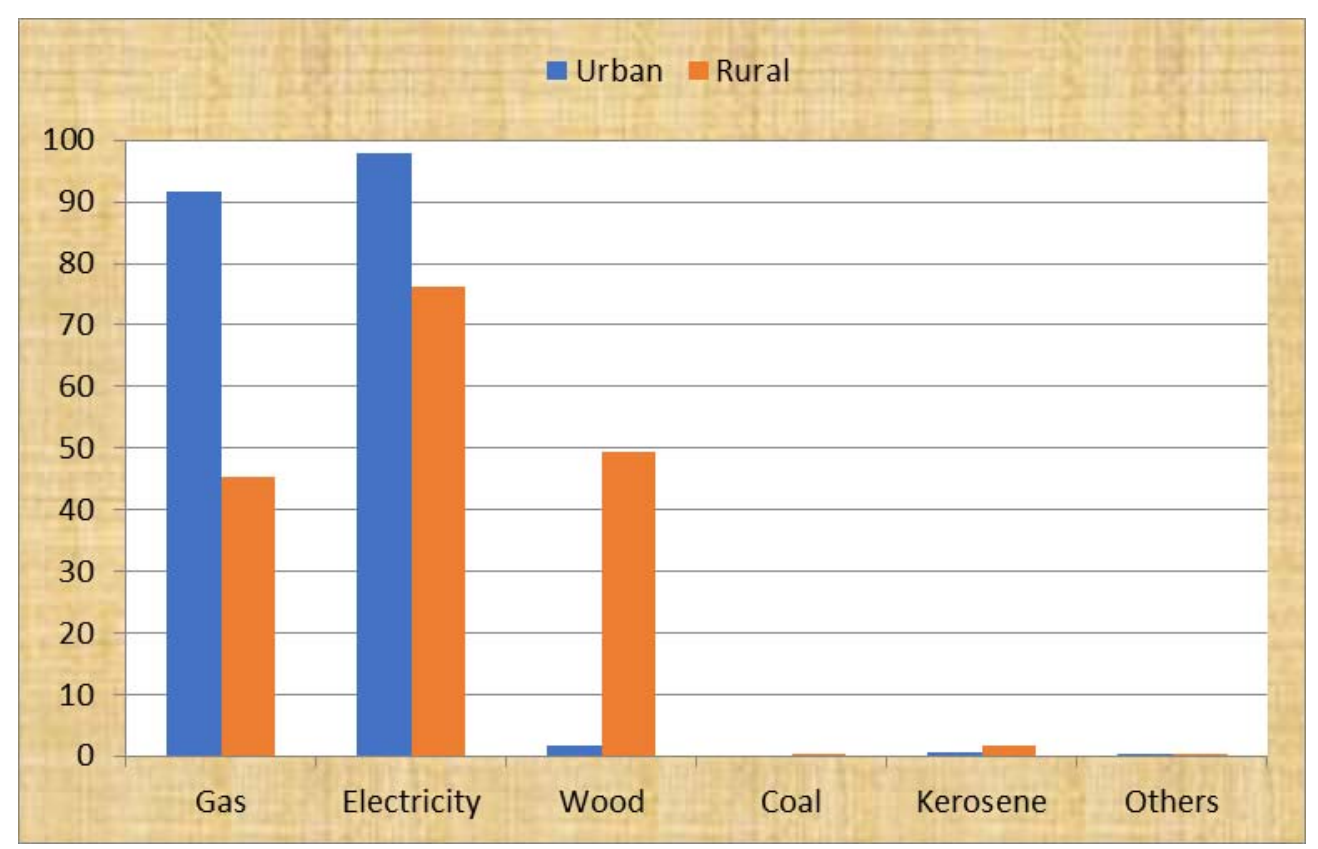

Fig. 2 Cooking sources of energy.

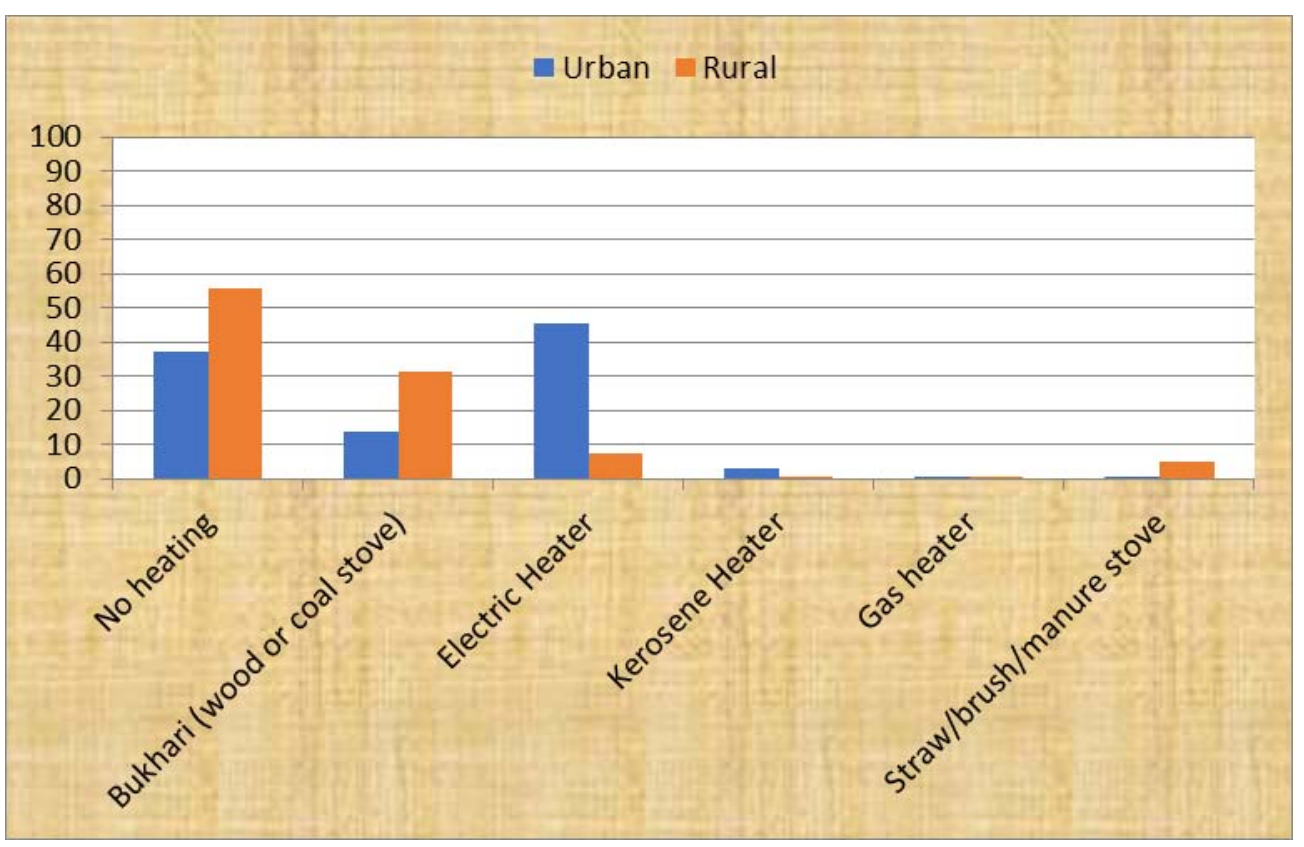

Fig. 3 Heating sources of energy.

kerosene or gas lamps for lighting [3].

Distribution of households in \%age by use and source of energy is shown in Fig. 1 for both urban and rural areas [3].

The energy sources most widely used for cooking are electricity ( $84 \%$ of households), gas (61\%), and wood (33\%). Electricity is the most widely used source of energy for cooking in both the urban (98\%) and rural (76\%) areas. The use of gas for cooking is proportionally greater in the urban areas (92\% of households) than in the rural areas (45\%) as shown in Fig. 2. Wood is used for cooking by about half of rural households (49\%) but is hardly used for that purpose in the urban areas [3]. Solid fuels include coal and wood biomass, charcoal, crop residues, and animal dung. The use of these traditional fuels for cooking 
serves as a proxy for indoor pollution, associated with the increased incidence of diseases such as acute lower respiratory infections among children, chronic obstructive pulmonary disease, and, where coal is used, lung cancer. Since about half of rural households use wood for cooking, the solid fuel of interest in controlling indoor pollution is wood used for cooking in the rural areas.

From above it is very clear that Bhutanese uses maximum electricity for all 3 purposes: lighting, cooking and heating (Fig. 3). Hence the focus is more on electricity then other sources of energy.

\subsection{Energy}

\subsubsection{Price/Tariff}

Bhutan's low cost electricity will likely encourage increased domestic consumption of electricity, which may occur with an increase in residential and commercial use of electrical appliances, and a potential increase in electricity use by newly attracted energy-intensive industries.

\subsubsection{Availability of Power}

Bhutan depends more on hydro power. It has excess power generation and exports all the extra power to India. However this is not only the means for stable future energy. There are other options like going for other alternatives power generation (solar, wind, biomass etc.) and reducing the energy demand by using the high efficiency electrical equipment and load balancing. Customers are most affected by this. Government should give awareness and benefits in cost saving from consumer's point of view along with country benefit in getting high foreign currency.

\subsubsection{Awareness}

An understanding of end users energy pattern is important for energy management. Many of new consumers are low income groups with low consumption. They also do not have much experience in utilization of electrical energy and will follow similar trend throughout the village with peak load in evening and morning hours. Lots of voltage swing occurs, power factor varies and hence the power quality. It may affect the regional load profile and size of equipment rating increases in substations.

\subsection{Policy}

\subsubsection{Benefits of Energy Conservation}

Bhutan enjoys renewable electrical energy generation. Energy saved is energy produced. Therefore through our effort, whatever we save is the energy produced for our neighbouring country. According to home energy audit, one house saves 1.01 kWh per day [4], which amounts to $365.65 \mathrm{kWh}$ per year. As the number of household is 127,942 [3], the total energy saved in a year is $47,165,818 \mathrm{kWh}(47.17$ $\times 10^{6}$ units). This earns $\mathrm{Nu} 94.33$ million Indian currency as the power is exported to India. This also means roughly 23,583 tons of carbon trading per year. Retrofitting of buildings offers significant opportunities for reducing global energy consumption and greenhouse gas emissions and is considered as one of main approaches to achieve sustainability in the built environment [5].

\subsubsection{Incentives}

When a household can save 365.65 units of energy per year only from lighting, the income increases and at the sometime government earns $\mathrm{Nu} 737.3$ (365.65 units $\times \mathrm{Nu} 2$ ) Indian currency plus the $184.3 \mathrm{~kg}$ of $\mathrm{CO}_{2}$. However majority of people are not keen to invest in new EE lamps. Energy efficiency measures were done in Sweden and it was mentioned that majority of respondent (70-90\%) did not intend to improve the building envelop as they were satisfied with their existing components [6]. Bhutan government needs to invest and provide incentives for energy efficiency investment.

Government may come up with policies and projects like (i) low income energy efficiency programme, (ii) renewable energy bonus scheme, (iii) energy efficient home incentives, (iv) living greener incentives, (v) phasing out inefficient bulbs, (vi) energy auditing of government buildings, (vii) energy 
efficiency best practices programme for industries. The Recently Draft National Energy Efficiency Policy is under discussion for adoption.

\subsubsection{Regulations}

Many countries have regulation in place not to use incandescent lamps. Regulation has to be made for energy efficiency. As mentioned above a household could save Nu 737.3 per years at present electricity tariff. Over the last few year, we have seen, the tariff increasing $10 \%$ ever year [7]. If this continues every household's energy expenditure is going to increase. Therefore some regulations like no incandescent lamps, use of star rating appliances etc. need to be in place. Even US has found worth replacing bulbs with CFL and LED lamps and lighting efficiency goals have been emphasized in US energy efficiency policies [8].

\subsubsection{Energy Efficiency Lending}

Efforts from the financial institutions are equally important in promoting energy efficiency investments. New initiatives and finance schemes need to be developed by financial institutions. World Banks and Asian Development Bank are helping developing countries like Bhutan to go for renewable energy, energy efficiency, clean energy and help reduce $\mathrm{CO}_{2}$ emission and help climate change. Similarly our financial institution needs to come up with similar ideas and help small customers and companies.

Similarly major companies need to support the institute like College of Science and Technology and help develop research capacities. In any developed countries, research activities are either supported by industries or by the government. It should be looked at long term benefits and not the short term benefits.

\subsection{Customer}

\subsubsection{Affordability}

Sixty-nine percent of Bhutanese still live in rural areas. Their income is low as they depend mostly on agriculture including livestock and forestry. Even in urban areas, many are in poor conditions due to large family members and high dependency ratio. According to the SDG country report 2012, the poverty line is $\mathrm{Nu} 1,704.84$ per person per month and $12 \%$ of population live under poverty [9]. Among these $16.7 \%$ of rural population are below poverty line [9]. Electricity for all has now connected every house with electricity. It becomes extremely difficult for many to replace with high efficiency lamps. The present government has given $100 \mathrm{kWh}$ (units) free per month to rural areas, but what happens when new government comes into power in 2018? It may be worth to subsidize high efficiency lamps which will ultimately reduce electricity bills.

\subsubsection{Types of Houses}

The house in Bhutan varies from place to place and of course with earning. The houses are not designed for energy efficiency heating system. Their doors and windows are not properly sealed. Neither are they designed to get maximum day light. Some houses are so closed to each other, such that we have to put on the light for $24 \mathrm{~h}$ in some rooms.

\subsubsection{Amount of Energy Consumed}

As per the South Asian Association for Regional Corporation (SAARC) group on statistics (2014) household energy consumption of Bhutan is 252.7 kWh per capital in 2012 [10]. This is the highest among the SAARC countries.

\subsubsection{In-House Energy Management}

Unlike many developed countries, energy management is not a big issue. With $10 \%$ increase in electricity tariff every year, many have become conscious but still lag proper energy managements. Some kind of workshop and demonstration is urgently required.

\subsection{Market}

\subsubsection{Easy Availability}

The market condition is very vital in energy efficiency investment. Firstly Bhutan is producing clean and green energy with huge market in India. The economic and business conditions are still not very 
attractive for energy efficiency investment. Bhutan peak demand is roughly $350 \mathrm{MW}$ power. Low voltage customer consumes around $21 \%$ which is very low [11].

\subsubsection{Foreign Currency (Indian Currency)}

When energy is saved in Bhutan, it will be exported to India. Any amount of energy saved will therefore earn proportionately increase Indian currency reserve for Bhutan.

\subsection{Building Architecture}

\subsubsection{Architecture of Building}

Traditional Bhutanese houses are made of up ramped mud and timbers. A modern house uses lots of bricks, timber and glasses. House insulation has not picked up in Bhutan beside cold climate in winter.

\subsubsection{Regulations}

Present regulation has focused on keeping traditional looks of the building.

\subsubsection{Energy Efficiency Design}

Bhutanese people enjoy cheap electricity in the world. At the same time $12 \%$ of Bhutanese live below poverty line. The present house does not have nice seal to prevent movements of air in and out of building, no proper insulation, nor good day light entrance.

\subsection{Technology}

\subsubsection{Technology around/Neighbouring Countries}

Everyone knows energy consumption could be significantly reduced with the use of energy efficient technology. Adam B. Jaffe et al. have mentioned the importance and role of new technology in solving energy issues. Numbers of technologies are cost effectives but not commonly used by customers [12]. Due to small population and market, Bhutan needs to depend on neighbouring country India technology for various reasons like easy availability, maintenance, cost etc. Most of the appliances used are very simple with low energy efficiency. In urban areas Bhukari (fire place) is being getting replaced with electric heater.

\subsection{Risk Involvement}

\subsubsection{Investment Return}

Companies who decide not to invest in energy efficiency projects would appear to be operating in the best interests of the shareholder. When a project is proposed with energy efficiency, the payback period increases and hence the project does not get approved. Therefore the innovation and innovative ideas are lost. The capital cost of the project increases.

Likewise, every one compares between investment and annual energy cost saving. It is a risk that energy efficiency investment may or may not produce the expected return on investments. For lighting replacing incandescent lamps with LED lamps is a better option with a payback period of 3 years. However it is very challenging to convince the rural population (69\%) and even if convinced, difficult to retrofit due to their affordability as EE lamps cost more.

\section{Conclusion}

Energy efficiency is a burning topic across the world. Bhutan produces huge amount of green and clean electrical energy. But due to low income and people below poverty line, they find difficult to pay electricity bills. Many would prefer to have energy efficiency mainly to reduce their monthly electricity bills. However not many would prefer to invest as the return is very slow or poor. Customers are also influenced by external factors like government policies, technologies around and availability of such materials. Policies must be created towards energy efficiency investments. Government building may be encouraged first to demonstrate such advantages. Economics incentives, investment incentives or subsidised EE lamps may encourage them towards energy efficiency investments.

Greenhouse gas and carbon trading need to be evaluated so that government will be interested to invest on such projects. Awareness programmes need 
to be organised across the country. Individual service provider should not look at their present revenue earning but look at future of the country considering all aspects.

\section{Future Research Work}

This paper could not discuss all in details due to lack of time and fund. The research topic may be slightly changed to "Views and Factors Affecting Energy Efficiency Investments-A Case Study of Bhutan". Sponsor may be looked to find more critically besides house owner perceptions, affordability, retrofit services, technical competency and policies.

\section{References}

[1] Chhetri, R., et al. 2009. "Pico-Hydro Power Plant an Option for Bhutan.” International Journal, BITM (Bengal Institute of Technology \& Management) Transaction on EECC, ISSN No. 0974-9527, 1 (4).

[2] Dorji, T. 2013. The Energy State of Nation, Kuenselonline, October 11, 2013. http://www.kuenselonline.com/the-energy-state-ofthe-nation/.
[3] Asian Development Bank \& National Statistics Bureau, Thimphu. 2012. Bhutan Living Standards Survey Report.

[4] Roshan, C., et al. 2014. "Home Energy Audit-A Case Study of Phuentsholing, Bhutan.” In Proceedings of the International Conference on Communication Systems and Network Technologies 20, NITTR Bhopal, 7-9 April 2014, pp. 1022-5.

[5] Ma, Z., et al. 2012. "Existing Building Retrofits: Methodology and State of the Art.” Energy and Buildings 55: 889-902.

[6] Nair, G. 2012. "Implementation of Energy Efficiency Measures in Swedish Single-Family Houses.” Doctoral thesis, Mid Sweden University, Sundsvall, Sweden.

[7] http://www.bea.gov.bt/.

[8] Min, J., et al. 2015. “Assessing Regional Differences in Lighting Heat Replacement Effects in Residential Buildings across the United States.” Applied Energy 141: 12-8.

[9] SAARC Development Goal-Country Report 2013, Gross National Happiness Commission, Bhutan.

[10] http://www.saarcstat.org/content/saarc-figures.

[11] Ulmasova, S. 2013. "The Hydro-Electrical Power Sector in Bhutan: An Economic Assessment.” Master thesis, University of Rhode Island.

[12] Jaffe, A. B., and Stavins, R. N. 1994. "Energy_Efficiency Investments and Public Policy." The Energy Journal 15 (2): 43-65. 